\title{
Evaluation of 95-Gene Classifier of Formalin-Fixed Paraffin-Embedded Tissues in ER-Positive, HER2- Negative, and Node-Negative Breast Cancer
}

Hiroko Yamashita ( $\nabla$ hirokoy@huhp.hokudai.ac.jp )

Hokkaido University Hospital https://orcid.org/0000-0003-4281-8727

Kanako C. Hatanaka

Hokkaido University Hospital: Hokkaido Daigaku Byoin

Keisuke Yamagishi

Sysmex Corp: Sysmex Kabushiki Kaisha

Yuria Saito

Sysmex Corp: Sysmex Kabushiki Kaisha

Kengo Hamasaki

Sysmex Corp: Sysmex Kabushiki Kaisha

Mitsuru Taniguchi

Sysmex Corp: Sysmex Kabushiki Kaisha

\section{Asami Okumura}

Hokkaido University Hospital: Hokkaido Daigaku Byoin

\section{Ayae Nange}

Hokkaido University Hospital: Hokkaido Daigaku Byoin

Yoshihiro Matsuno

Hokkaido University Hospital: Hokkaido Daigaku Byoin

Yutaka Hatanaka

Hokkaido University Hospital: Hokkaido Daigaku Byoin

\section{Research article}

Keywords: 95-gene classifier, recurrence, ER-positive node-negative breast cancer, prediction model

Posted Date: May 4th, 2021

DOI: https://doi.org/10.21203/rs.3.rs-436012/v1

License: (c) (i) This work is licensed under a Creative Commons Attribution 4.0 International License.

Read Full License 


\section{Abstract}

Background A subset of patients with estrogen receptor (ER)-positive, HER2-negative, and node-negative breast cancer experience recurrences. Predicting patients who will have recurrences within 5 years of surgery is essential so that patients can be selected to receive adjuvant chemotherapy. The 95-gene classifier (95-GC) has been validated as a method to differentiate patients into high and low-risk groups for early recurrence.

Methods In this study, we performed 95-GC analysis on 56 formalin-fixed paraffin-embedded (FFPE) tissue samples from patients who underwent surgery for ER-positive, HER2-negative, and node-negative breast cancer and did not receive adjuvant chemotherapy. We associated the obtained high- and low-risk groups with clinicopathological characteristics and recurrence-free survival (RFS).

Results We classified 12 out of 56 patients into the high-risk recurrence group. We found significantly higher KI67 scores in patients in the high-risk group. Other clinicopathological characteristics were not associated with the 95-GC risk groups. Patients in the 95-GC low-risk group had a significantly better prognosis than those in the high-risk group $(p=0.0387)$. The 5 -year RFS rate was $97.6 \%$ in the low-risk group and $74.1 \%$ in the high-risk group, while the 10 -year RFS rates were $90.1 \%$ and $74.1 \%$, respectively.

Conclusions Our study shows that the 95-GC score can accurately predict RFS within 5 years of surgery for ER-positive, HER2-negative, and node-negative breast cancer using FFPE tissue samples. These prediction models could help assign patients to the most effective treatment regimen.

\section{Background}

Over the past decades, new strategies to complement therapies for early-stage breast cancer have improved disease outcomes.(1-3) For instance, within the first 5 years of diagnosis, chemotherapy in the adjuvant setting can reduce the recurrence risk.(3) Therefore, predicting the risk of early recurrence is vital to determine the appropriate type of chemotherapy treatment after surgery. Accurate diagnostic and prognostic prediction methods using clinicopathological characteristics are warranted to determine the best personalized treatment regimen for each patient.

In recent years, multi-gene assays, such as OncotypeDx ${ }^{\circledR}$ and MammaPrint ${ }^{\circledR}$, have made it possible to predict the prognosis of breast cancers.(4-7) However, a disadvantage of some of these methods is that patients are often classified into a low, intermediate, or high-risk group for recurrences. Choices in clinical practice for post-surgery treatment are challenged by this grouping, as it is unclear whether the intermediate group would benefit from adjuvant chemotherapy.

The 95-gene classifier (Curebest ${ }^{\text {TM }}$ 95GC Breast, Sysmex, Kobe, Japan) is a multi-gene assay that uses DNA microarray analysis to classify breast cancer patients as having a high or low risk of recurrence, based on the expression levels of 95 genes.(8) In this study, patients who were grouped into the low-risk group had a better outcome than those in the high-risk group. The use of the 95-gene classifier allows for 
a clear division into high and low risk, without referring to intermediate groups. This distinction aids treatment strategies in clinical practice.

The 95-GC method was initially optimized to be used for frozen tissue samples but has since been shown to also be effective and consistent in formalin-fixed paraffin-embedded (FFPE) specimens.(9) However, it has not yet been established whether the results obtained from FFPE tissue are also predictive of outcome. We hypothesized that the 95-GC can be accurately used on FFPE material to not only determine high or low risk of recurrence but also predict the outcome. In this study, we performed the 95-GC analysis on FFPE tissue specimens of 56 patients with ER-positive, HER2-negative, and node-negative breast cancer who did not receive adjuvant chemotherapy and compared 95-GC signatures with the outcome.

\section{Methods}

\section{Patients and cancer specimens}

We recruited 56 women with stage I or II breast cancer for this study. All patients were treated between 2005 and 2012 at Hokkaido University Hospital (Table 1). The institutional review board approved the study protocol and our study met the guidelines of the Declaration of Helsinki (1996). All patients provided written informed consent before treatment for the collection of surgically resected tumor tissues. The samples were collected continuously from all patients with ER-positive and HER2-negative invasive ductal carcinoma of the breast. All patients underwent mastectomy or lumpectomy, during which tumor samples were obtained. Patients received adjuvant endocrine therapy (tamoxifen with or without luteinizing hormone-releasing hormone agonist for premenopausal women and aromatase inhibitors for postmenopausal women) after surgery. We excluded patients treated with adjuvant or neoadjuvant chemotherapy.

FFPE tissues were stored at $4^{\circ} \mathrm{C}$ until the study was performed and four sections of $10 \mu \mathrm{m}$ thickness of FFPE specimens were obtained for RNA extraction.

\section{RNA extraction and DNA microarray analysis}

RNA extraction was performed using the RNeasy FFPE Kit according to the manufacturer's protocol (Qiagen, Hilden, Germany). The extracted RNA was synthesized into cDNA using the Ovation FFPE WTA Systems (Affymetrix, Santa Clara, CA, USA) and the Encore Biotin Module (Affymetrix) kits according to the manufacturer's instructions. The cDNA (100 ng) was then used for gene expression analysis by DNA microarray using the Human Genome U133 Plus 2.0 Array according to the manufacturer's instructions (Affymetrix).

\section{Immunohistochemistry}

Tissue sections were stained for Ki67 using a mouse monoclonal anti-human Ki67 antibody (MIB-1; Dako, Glostrup, Denmark) at 1:200 dilution, and the Dako FLEX Envision system for visualization of antibody binding. We assessed the labeling index (LI), which we defined as the percentage of invasive 
tumor cells $(>1,000)$ with nuclear staining.(10) All slides were scanned using NanoZoomer 2.0-HT (Hamamatsu Photonics, Hamamatsu, Japan) and Tissue Studio was used to perform the LI analysis (Definiens, Munich, Germany) automatically.

\section{Statistical analysis}

Risk scores for high and low recurrence groups were calculated based on the method by Naoi et al.(11) Recurrence-free survival (RFS) was defined as the time between surgery and recurrence, death, or end of follow-up. The Kaplan-Meier method was used to calculate RFS, and differences between groups were evaluated using the log-rank test. Spearman's rank correlation coefficient was used to evaluate the correlation between Ki67 LI and 95-GC. A univariate analysis was performed using the Cox proportional hazards model. The correlation between $95-\mathrm{GC}$ and clinicopathological factors was evaluated using Fisher's exact test (for age, menopausal status, $T$ stage, and grade) and the Mann-Whitney U Test (for ER, $\mathrm{PgR}$, and $\mathrm{Ki} 67 \mathrm{LI}) . \mathrm{P}<0.05$ was considered statistically significant.

\section{Results}

\section{Associations between 95-GC scores and clinicopathological factors}

Patient characteristics are shown in Table 1. We included 56 patients with ER-positive, HER2-negative, and node-negative breast cancer, of whom 46 patients (82\%) had stage I and 10 patients (18\%) had stage II breast cancer. Using the $95-\mathrm{GC}$ classifier, we classified all 56 patients into two groups according to risk of recurrence: a high-risk group $(n=12)$ and a low-risk group $(n=44)$. No correlations were observed between the groups with high and low risk based on age, menopausal status, T stage, grade, or ER and progesterone receptor (PgR) expression levels. In contrast, the KI67 (LI) was significantly higher in the high-risk group, with a median score of 20.6 as compared to 9.93 in the low-risk group $(p=0.0033)$. Additionally, we found a significant correlation between the 95-GC score and Ki67 LI (\%) using Spearman's Rank correlation coefficient $(p<0.0001)$ (Fig. 1). 
Table 1

Clinicopathological characteristics of included breast cancer patients

\begin{tabular}{|c|c|c|c|c|c|}
\hline \multirow{2}{*}{ Factors } & & \multicolumn{4}{|c|}{ 95-Gene classifier } \\
\hline & & Low & High & Total & $p$-value \\
\hline & & $(n=44)$ & $(n=134)$ & & \\
\hline \multirow[t]{2}{*}{ Age } & $\leq 50$ years & $12(71 \%)$ & $5(29 \%)$ & 17 & 0.4797 \\
\hline & $>50$ years & $32(82 \%)$ & $7(18 \%)$ & 39 & \\
\hline \multirow[t]{2}{*}{ Menopausal status } & Premenopausal & $11(69 \%)$ & $5(31 \%)$ & 16 & 0.2929 \\
\hline & Postmenopausal & $33(83 \%)$ & $7(17 \%)$ & 40 & \\
\hline \multirow[t]{2}{*}{ T stage } & $\mathrm{T} 1$ & $38(83 \%)$ & $8(17 \%)$ & 46 & 0.3707 \\
\hline & $\mathrm{T} 2$ & $6(60 \%)$ & $4(40 \%)$ & 10 & \\
\hline \multirow[t]{2}{*}{$\mathrm{ER}(\%)$} & Median & 100 & 100 & - & 0.991 \\
\hline & Min to Max & 50 to 100 & 30 to 100 & - & \\
\hline \multirow[t]{2}{*}{$\operatorname{PgR}(\%)$} & Median & 45 & 55 & - & 0.92 \\
\hline & Min to Max & 0 to 100 & 0 to 100 & - & \\
\hline \multirow[t]{3}{*}{ Grade } & 1 & 19 (86\%) & $3(14 \%)$ & 22 & 0.1816 \\
\hline & 2 & $25(76 \%)$ & $8(24 \%)$ & 33 & \\
\hline & 3 & 0 & $1(100 \%)$ & 1 & \\
\hline \multirow[t]{2}{*}{ Ki67 } & Median & 9.93 & 20.6 & - & 0.0033 * \\
\hline & Min to Max & 1.9 to 32.1 & 8.5 to 39.6 & - & \\
\hline
\end{tabular}

\section{Univariate analysis comparing 95-GC and other clinicopathological factors}

We performed a univariate analysis for all clinical characteristics and the 95-GC scores to determine which factors affect the development of recurrences (Table 2). The only factor with a significant association with recurrences was the 95-GC score, which had a hazard ratio of 11.09 (95\% Cl: $1.15-$ $106.87, p=0.0375$ ). None of the clinicopathological characteristics, except the $95-\mathrm{GC}$ score, was significantly correlated with recurrences. 
Table 2

Investigation of prognostic factors using univariate analysis (Cox proportional hazards model)

\begin{tabular}{|llllll|}
\hline Factors & & Hazard ratio & Lower 95 & Upper 95 & $p$-value \\
\hline Age & $>50$ vs. $\leqq 50$ & 0.45 & 0.06 & 3.22 & 0.4292 \\
\hline Menopausal status & Post vs. Pre & 1.33 & 0.14 & 12.8 & 0.8043 \\
\hline T stage & $\geqq T 2$ v T1 & N/A & - & - & - \\
\hline ER (\%) & Continuous variables & 0.96 & 0.92 & 1.00 & 0.0613 \\
\hline PgR (\%) & Continuous variables & 0.98 & 0.94 & 1.01 & 0.1560 \\
\hline Grade & 1 vs. 2 vs. 3 & 4.33 & 0.53 & 35.70 & 0.1734 \\
\hline Ki67 LI (\%) & Continuous variables & 1.09 & 1.00 & 1.18 & 0.0557 \\
\hline 95-GC & High vs. Low & 11.09 & 1.15 & 106.87 & $0.0375^{\star}$ \\
\hline
\end{tabular}

* $p<0.05$ is considered significant

\section{Prognostic value of $95-\mathrm{GC}$ risk groups}

Using the 95-GC classifier, we compared the prognosis of the 95-GC high and low-risk groups. Patients were followed up for 4-129 months, with a median of 87 months. We compared the RFS and found a significant prognostic value for the 95-GC risk groups. We found a significantly better prognosis in the 95GC low-risk group than in the high-risk group ( $p=0.0387)$. The 5-year RFS rate was $97.6 \%$ in the low-risk group and $74.1 \%$ in the high-risk group, while the 10 -year RFS rates were $90.1 \%$ and $74.1 \%$, respectively (Fig. 2).

\section{Discussion}

For clinical practice, it is essential to develop diagnostic tools to determine a patient's risk of developing recurrences to make the right therapeutic choices. While patients with ER-positive node-negative breast cancer have an overall good prognosis, $10-20 \%$ will develop recurrences.(12) This subset of patients would benefit from a combination treatment of endocrine therapy and chemotherapy to prevent relapse within 5 years of surgery, while patients not at risk of early recurrence require only adjuvant endocrine therapy.

Previous research (8) and indirect-comparative studies with OncotypeDx using Recurrence Online (11) have established that the 95-GC can be applied to frozen tumor tissue and is an effective early recurrence predictor for up to 5 years post-surgery. As such, it is used to identify cases in which chemotherapy 
should also be used.(13) While it has been established that the 95-GC can also be applied to FFPE material, data obtained from such samples have not been associated with prognostic outcomes.(9)

In our study, we defined the 95-GC risk groups using FFPE specimens from patients with cancer who had received postoperative endocrine therapy without chemotherapy. All specimens were ER-positive and HER2-negative and had infiltrations of at least $5 \mathrm{~mm}$ that were indicated for postoperative drug treatment. When obtained from FFPE tissue, the 95-GC was demonstrated to be effective as an early recurrence predictor for up to 5 years post-surgery. Additionally, we found a strong correlation between the 95-GC score and Ki67, another reliable predictor of early recurrence.

Our investigation into prognostic factors using univariate analysis showed the 95-GC is a prognostic factor for early recurrence. However, in the present study, we found one case with a recurrence after the first 5-year observation period. This patient was categorized by the 95-GC into the low-risk group. This may suggest that the 95-GC from FFPE cannot be used to predict late-stage recurrence after 5 years. Indeed, based on risk factors for early and late recurrence, ER-positive breast cancers with early and late recurrences are considered biologically different. $(14,15)$ Additionally, Ki67 has been suggested not to be a prognostic factor for late-stage recurrences. Therefore, a different signature may need to be discovered for the prediction of late-stage recurrences.(16)

Our study has a few limitations. The sample size of this study is relatively low, with only 12 patients classified in the high-risk group. This limits the results from the long-term survival analysis. Second, we did not perform a comparison between results obtained from FFPE material with frozen tissue from the same tumor. However, a previous study has established that 95-GC scores obtained from both FFPE and frozen material provide a good correlation.(9)

\section{Conclusions}

We demonstrated that the 95-GC score can accurately predict recurrence within 5 years of surgery for ERpositive, HER2-negative, and node-negative breast cancer using FFPE tissue samples in patients who did not receive adjuvant chemotherapy. Future studies should focus on prediction models for late recurrences. These prediction models help assign patients to the most effective treatment regimen.

\section{Abbreviations}

ER: Estrogen receptor

FFPE: formalin-fixed paraffin-embedded

LI: labeling index

PgR: progesterone receptor

RFS: recurrence-free survival 


\section{Declarations}

\section{Ethics approval and consent to participate}

Ethical approval was obtained from the Ethics Committee of Hokkaido University Hospital (No. 017-0415) and Sysmex Corporation (IRB No. 2017-57), and the study was conducted as per the current relevant laws of Japan. A comprehensive informed consent was obtained for each patient before surgery.

\section{Consent for publication}

Not applicable.

\section{Availability of data and materials}

The datasets used and/or analyzed during the current study are available from the corresponding author on reasonable request.

\section{Funding}

All sources (body in the design of the study and collection, analysis, and interpretation of data and in writing the manuscript) of funding of the study was by Sysmex Corporation.

\section{Authors' contributions}

All authors contributed to the study conception and design, material preparation, and data collection. Analysis was conducted by $\mathrm{YS}, \mathrm{KY}$, and $\mathrm{KH}$. The first draft of the manuscript was written by $\mathrm{HY}, \mathrm{YH}$, and $\mathrm{KH}$. $\mathrm{HY}$ and $\mathrm{YH}$ commented on previous versions of the manuscript. All authors read and approved the final manuscript.

\section{Acknowledgments}

Editorial support, in the form of medical writing, assembling tables and creating high-resolution images based on authors' detailed directions, collating author comments, copyediting, fact-checking, and referencing, was provided by Editage, Cactus Communications, and funded by Sysmex Corporation.

\section{References}

1. Early Breast Cancer Trialists' Collaborative Group (EBCTCG). Aromatase inhibitors versus tamoxifen in early breast cancer: patient-level meta-analysis of the randomised trials. Lancet Lond Engl. 2015 Oct 3;386(10001):1341-52.

2. Early Breast Cancer Trialists' Collaborative Group (EBCTCG), Davies C, Godwin J, Gray R, Clarke M, Cutter $D$, et al. Relevance of breast cancer hormone receptors and other factors to the efficacy of adjuvant tamoxifen: patient-level meta-analysis of randomised trials. Lancet Lond Engl. 2011 27;378(9793):771-84. 
3. Palmieri C, Jones A. The 2011 EBCTCG polychemotherapy overview. Lancet Lond Engl. 2012 Feb 4;379(9814):390-2.

4. Paik S, Shak S, Tang G, Kim C, Baker J, Cronin M, et al. A multigene assay to predict recurrence of tamoxifen-treated, node-negative breast cancer. N Engl J Med. 2004 Dec 30;351(27):2817-26.

5. Paik S, Tang G, Shak S, Kim C, Baker J, Kim W, et al. Gene expression and benefit of chemotherapy in women with node-negative, estrogen receptor-positive breast cancer. J Clin Oncol Off J Am Soc Clin Oncol. 2006 Aug 10;24(23):3726-34.

6. van 't Veer LJ, Dai H, van de Vijver MJ, He YD, Hart AAM, Mao M, et al. Gene expression profiling predicts clinical outcome of breast cancer. Nature. 2002 Jan 31;415(6871):530-6.

7. van de Vijver MJ, He YD, van't Veer LJ, Dai H, Hart AAM, Voskuil DW, et al. A gene-expression signature as a predictor of survival in breast cancer. N Engl J Med. 2002 Dec 19;347(25):1999-2009.

8. Naoi Y, Kishi K, Tanei T, Tsunashima R, Tominaga N, Baba Y, et al. Development of 95-gene classifier as a powerful predictor of recurrences in node-negative and ER-positive breast cancer patients. Breast Cancer Res Treat. 2011 Aug;128(3):633-41.

9. Naoi Y, Saito Y, Kishi K, Shimoda M, Kagara N, Miyake T, et al. Development of recurrence risk score using 95-gene classifier and its application to formalin-fixed paraffin-embedded tissues in ER-positive, HER2-negative and node-negative breast cancer. Oncol Rep. 2019 Dec;42(6):2680-5.

10. Yoshioka T, Hosoda M, Yamamoto M, Taguchi K, Hatanaka KC, Takakuwa E, et al. Prognostic significance of pathologic complete response and Ki67 expression after neoadjuvant chemotherapy in breast cancer. Breast Cancer Tokyo Jpn. 2015 Mar;22(2):185-91.

11. Naoi Y, Kishi K, Tsunashima R, Shimazu K, Shimomura A, Maruyama N, et al. Comparison of efficacy of 95-gene and 21-gene classifier (Oncotype DX) for prediction of recurrence in ER-positive and nodenegative breast cancer patients. Breast Cancer Res Treat. 2013 Jul;140(2):299-306.

12. Park S, Koo JS, Kim MS, Park HS, Lee JS, Lee JS, et al. Characteristics and outcomes according to molecular subtypes of breast cancer as classified by a panel of four biomarkers using immunohistochemistry. The Breast. 2012 Feb;21(1):50-7.

13. Tsunashima R, Naoi Y, Kishi K, Baba Y, Shimomura A, Maruyama N, et al. Estrogen receptor positive breast cancer identified by 95 -gene classifier as at high risk for relapse shows better response to neoadjuvant chemotherapy. Cancer Lett. 2012 Nov 1;324(1):42-7.

14. Ogiya A, Yamazaki K, Horii R, Shien T, Horimoto Y, Masuda N, et al. Post-relapse survival in patients with the early and late distant recurrence in estrogen receptor-positive HER2-negative breast cancer. Breast Cancer Tokyo Jpn. 2017 May;24(3):473-82.

15. Yamashita H, Ogiya A, Shien T, Horimoto Y, Masuda N, Inao T, et al. Clinicopathological factors predicting early and late distant recurrence in estrogen receptor-positive, HER2-negative breast cancer. Breast Cancer Tokyo Jpn. 2016 Nov;23(6):830-43.

16. Tsunashima R, Naoi Y, Shimazu K, Kagara N, Shimoda M, Tanei T, et al. Construction of a novel multi-gene assay (42-gene classifier) for prediction of late recurrence in ER-positive breast cancer patients. Breast Cancer Res Treat. 2018 Aug;171(1):33-41. 
Figures

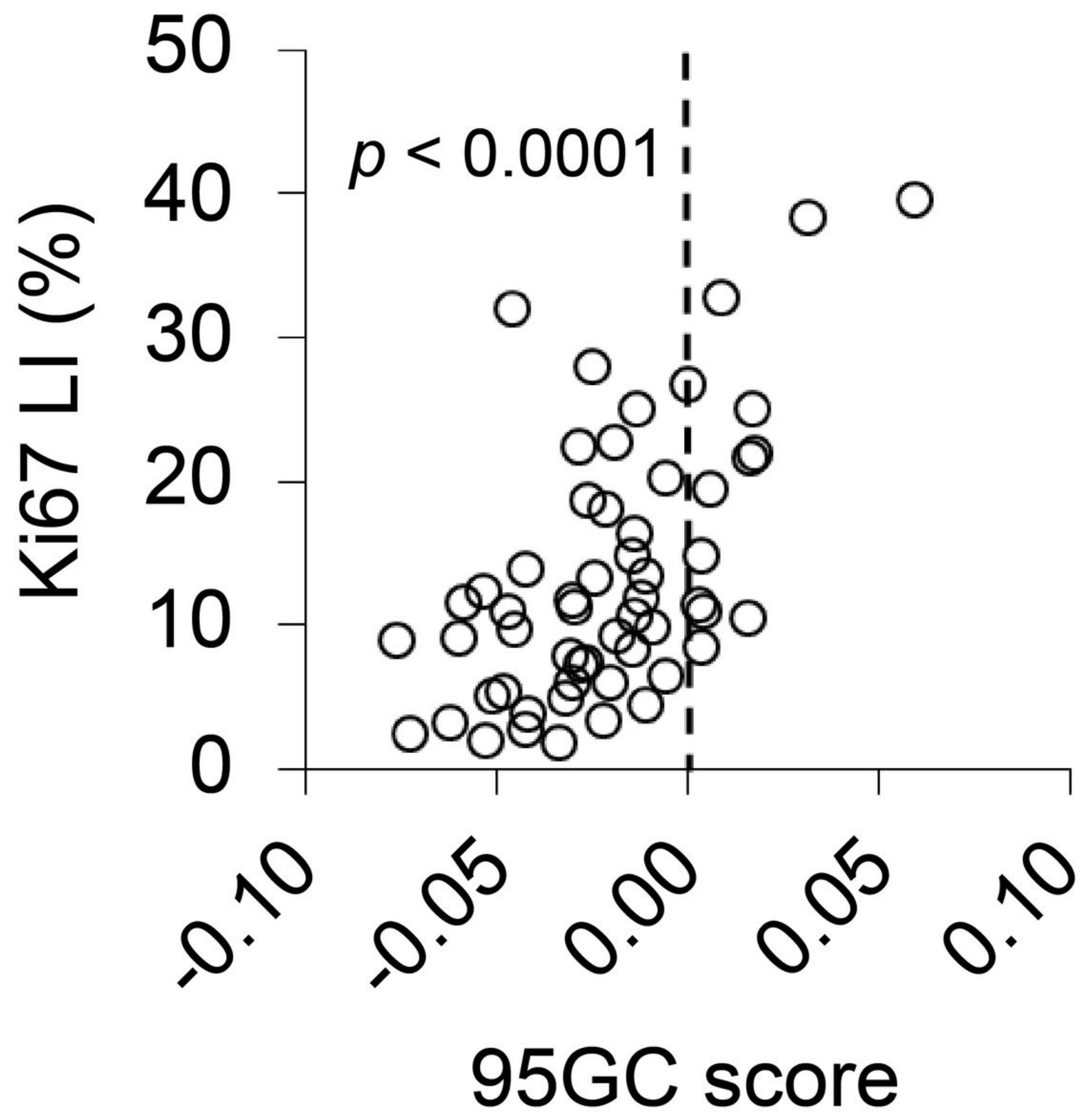

Figure 1

Spearman's rank correlation between 95-gene classifier (95-GC) score and Ki67 labeling index (LI) 


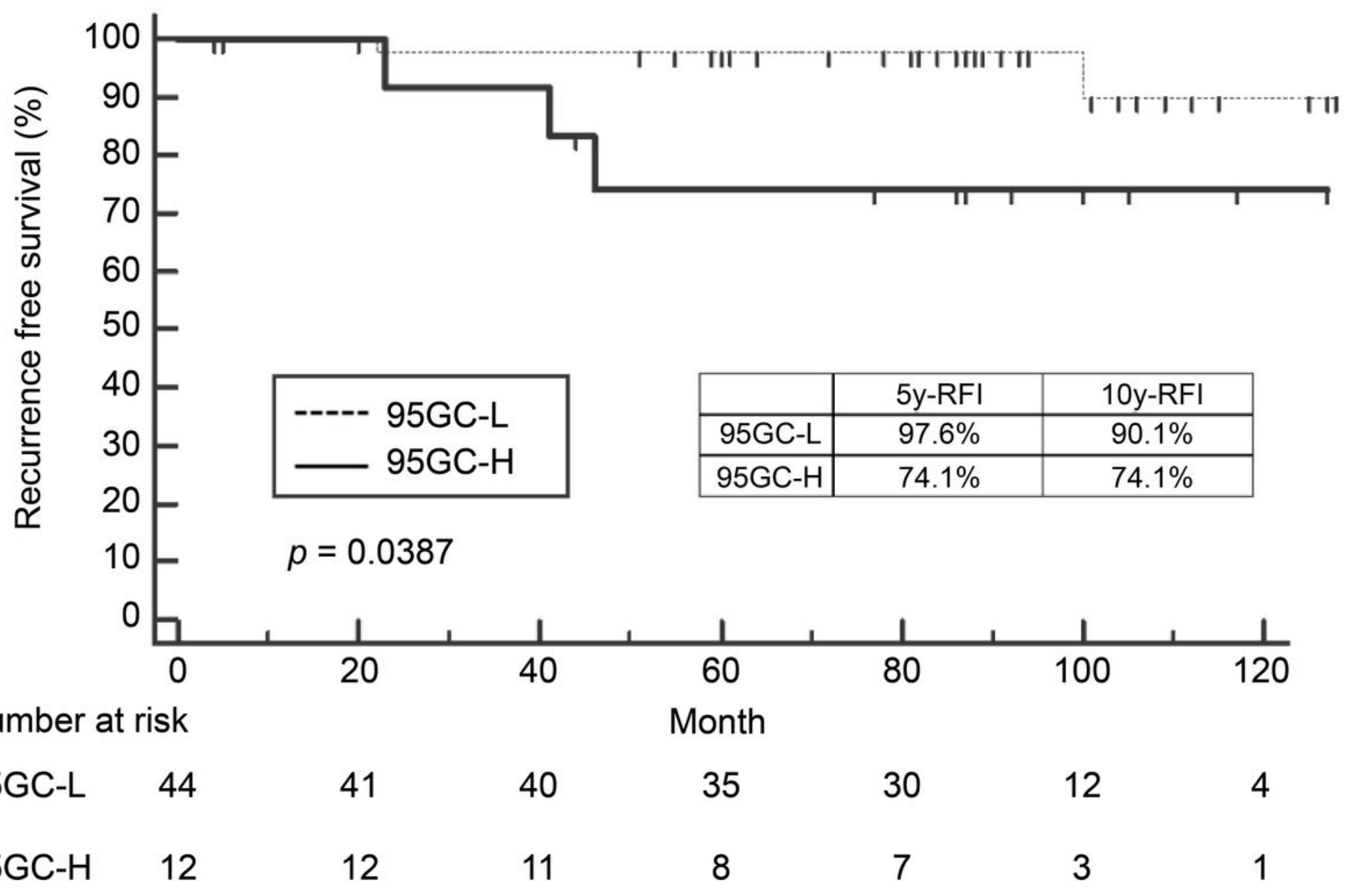

Figure 2

: Kaplan-Meier analysis of recurrence-free survival based on 95-gene classifier (95-GC) high (solid line) and low risk (dot line) groups (Log-rank test) 